\title{
Synthesis and Properties of Oligodeoxynucleotides Carrying 2-Aminopurine
}

\author{
Carme Fàbrega, Santiago Grijalvo and Ramon Eritja*
}

\begin{abstract}
Institute for Research in Biomedicine (IRB Barcelona), Institute for Advanced Chemistry of Catalonia (IQAC), Spanish Research Council (CSIC), Networking Centre on Bioengineering, Biomaterials and Nanomedicine (CIBER-BBN), Baldiri Reixac 10, E-08028 Barcelona, Spain
\end{abstract}

\begin{abstract}
The use of benzoyl, isobutyryl and dimethylaminomethylidene groups for the protection of the exocyclic amino function of 2-aminopurine during oligonucleotide synthesis has been investigated. Best results in the synthesis were obtained with the monomers of 2-aminopurine protected with the isobutyryl group.
\end{abstract}

Keywords: Amino protection, 2-aminopurine, DNA, mutagenesis, oligonucleotide, solid-phase synthesis.

\section{INTRODUCTION}

Oligonucleotides carrying non-natural bases are important tools for the determination of the molecular basis of mutagenesis. Furthermore, their special properties are used for structural determination of nucleic acids and proteins that bind nucleic acids [1].

2-Aminopurine (P, Fig. 1), an isomer of adenine in which the exocyclic amino group is located at position 2 instead of position 6, can form two hydrogen-bonded base pairs with thymine which are similar to the Watson-Crick A: T base pair $[2,3]$. In the 2-aminopurine: thymine base pair, one of the hydrogen bonds occurs in the minor groove instead of in the major groove. Several groups have taken advantage of this difference to characterize DNA-protein interactions [4, 5] and DNA bending [6, 7]. Due to the fluorescent properties of 2-aminopurine, this nucleobase is a useful local probe to study enzymes that interact with DNA, such as DNA polymerases [8-11], helicases [12] and DNA methylases [13,14] as well as in DNA structural studies [15, 16]. 2-Aminopurine can also form base pairs with adenine [17] and cytosine [2, $15,18,19]$ but not with guanine [20]. The formation of 2aminopurine: cytosine base pair results in transition mutations during DNA replication [21, 22]. NMR studies showed that 2-aminopurine: cytosine base pair adopts a wobble geometry at neutral and high $\mathrm{pH}[18,19]$.

The preparation of oligonucleotides carrying 2aminopurine was first described by Eritja et al. [20]. In this method, 2-aminopurine-2'-deoxyribonucleotide was prepared enzymatically from the free base [23], and the amino function was protected with the isobutyryl (ibu) group by analogy with 2'-deoxyguanosine (dG) [20]. Afterwards, the synthesis of 2-aminopurine phosphoramidite protected with the benzoyl (Bz) group was described starting from dG [24]. In this method, dG was protected with the Bz group, converted to the 6-hydrazino derivative which was reduced with silver

*Address correspondence to this author at the Institute for Research in Biomedicine (IRB Barcelona), Institute for Advanced Chemistry of Catalonia (IQAC), Spanish Research Council (CSIC), Networking Centre on Bioengineering, Biomaterials and Nanomedicine (CIBER-BBN), Baldiri Reixac 10, E-08028 Barcelona, Spain; Tel: +34932045942; Fax: +34932045904; E-mail: ramon.eritja@irbbarcelona.org
(I) oxide [24]. This method is easily scaled-up and detailed protocols have been published $[25,26]$. The $\mathrm{Bz}$ group was also selected for the protection of the 2-amino function during the synthesis of oligoribonucleotides containing 2aminopurine [27]. The synthesis of the ibu derivative of 2aminopurine-2'-deoxyriboside has been described by reduction of 6-chloroguanosine [28] and thioguanosine [29]. In addition, oligodeoxynucleoside methylphosphonates containing 2-aminopurine have been prepared using the base-labile phenoxyacetyl (PAC) group for the protection of the amino function of 2-aminopurine [30].

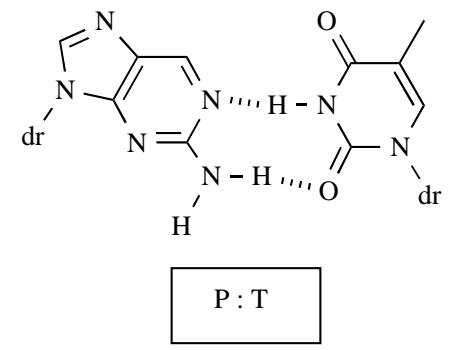

Fig. (1). Scheme of the hydrogen-bonding between 2-aminopurine and thymine.

A major concern for these authors was the high stability to ammonia of the Bz-protected derivative of 2-aminopurine, produced following the McLaughlin's protocol [28, 30]. In this sense, the preparation of the PAC-protected derivative of 2-aminopurine solved this problem, however implied a long synthetic route in which the Bz group is first introduced and then removed to allow the introduction of the PAC protecting group [30]. Finally, the preparation of oligonucleotides containing ${ }^{15} \mathrm{~N}$-2-aminopurine has been described using 2fluoropurine-2'-deoxynucleoside as convertible nucleoside [31]. However, this method is difficult to scale-up due to the enzymatic preparation of the 2-fluoropurine derivative.

In this paper, we describe the preparation of the isobutyryl derivative of 2-aminopurine-2'-deoxyriboside using McLaughlin's synthetic route [24] and we compare the use of the $\mathrm{Bz}$, ibu and dimethylaminomethylidene (dmf) protecting groups for the amino function of 2-aminopurine. 


\section{RESULTS AND DISCUSSION}

\section{Synthesis of $N^{2}$-Protected Derivatives of 2-Aminopurine- 2'-Deoxyriboside}

Starting from dG, $N^{2}$-Bz-2-aminopurine-2'-deoxyriboside was prepared as previously described [24-26]. The key step in this method was the treatment of a guanine derivative which has the hydrazino group at position 6 with silver oxide. The preparation of the 6-hydrazino derivative was performed by the activation of position 6 with the 2,4,6triisopropylbenzenesulfonyl (TPS) group, followed by nucleophilic displacement with hydrazine. During these reactions, the 3'- and 5'-hydroxyl groups and the 2-amino group were protected with the Bz group. After the silver oxide reaction 3'-, 5'-benzoate esters were selectively hydrolyzed giving the $N$-2-benzoylated derivative.

The $N^{2}$-Bz derivative was reported to be too stable for oligonucleotide synthesis by several authors [28, 30]. For this reason, and using a similar reaction scheme, $N^{2}$-ibu-2aminopurine-2'-deoxyriboside was prepared (Fig. 2). All reactions went to completion as described for the Bz derivative, giving a major product that was isolated in good yields.
NMR data of intermediates was in agreement with the proposed structures. The isobutyryl-protected intermediates were stable under the reaction conditions.

A similar scheme was applied to commercially available 5'-O-dimethoxytrityl (DMT)- $N^{2}$-ibu-dG. In this case, the starting material was carrying two of the groups needed for oligonucleotide synthesis: the DMT and the ibu groups. During the activation of position 6 with TPS-Cl, the free 3'hydroxyl group was protected with the trimethylsilyl group. Unfortunately, the presence of the bulky and labile DMT group at the 5 ' position slowed down the reaction, and the products were recovered in low yields. Moreover, the ibu group was lost during the treatment with silver oxide, due to the long time needed for this reaction and, 5'-O-DMT-2aminopurine deoxyriboside (5, Fig. 3) was isolated instead of the desired 2-aminopurine derivative carrying the DMT and the ibu groups.

Compound 5 was the starting material for the preparation of the 2-aminopurine derivative carrying the $\mathrm{dmf}$ group. This group has been reported as a protecting group of 2-amino function of $\mathrm{dG}$ in oligonucleotide synthesis, because it is

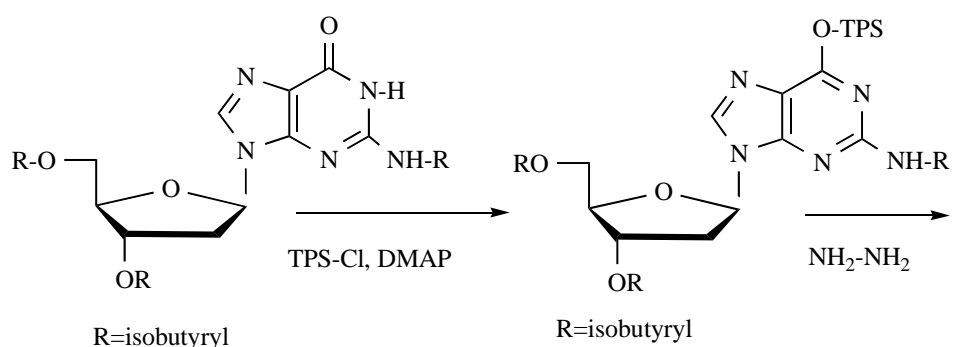

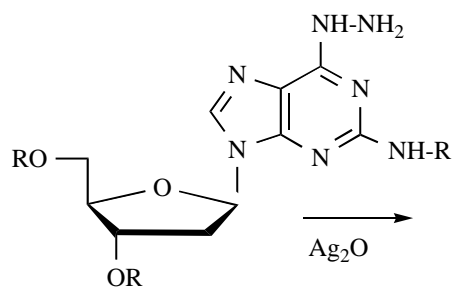

$\mathrm{R}=$ isobutyryl

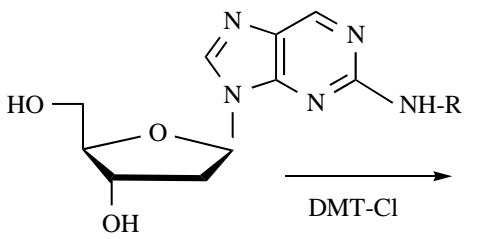

2 R=isobutyryl

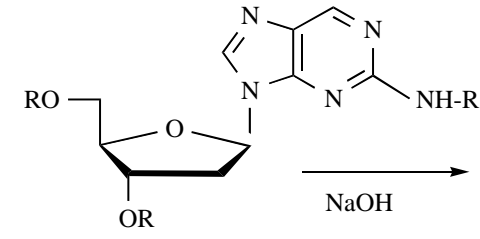

$1 \mathrm{R}=$ isobutyryl

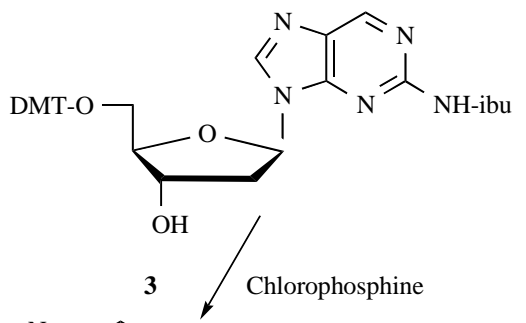

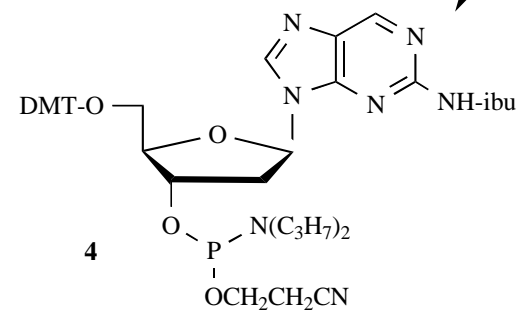

Fig. (2). Synthetic scheme used for the preparation of isobutyryl protected 2-aminopurine phosphoramidite. 
more labile than the ibu group $[32,33]$. Recently, the phosphoramidite derivative of 2-aminopurine carrying the $\mathrm{dmf}$ group has become commercially available. Treatment of compound 5 with dimethylformamide dimethyl acetal yielded compound 6, that was treated with succinic anhydride. The resulting hemisuccinate was coupled to controlled pore glass functionalized with amino groups.

\section{Depurination and Stability Studies}

Protected (Bz, ibu) 2-aminopurine 2'-deoxyriboside derivatives carrying the DMT group at 5' position were succinylated and attached to controlled pore glass supports following standard protocols [34]. Stability of the different protecting groups to ammonia was studied by treatment of the different nucleoside supports with concentrated ammonia in order to simulate oligonucleotide synthesis conditions. Prior to ammonia treatment the supports were treated with a $3 \%$ trichloroacetic acid (TCA) solution to eliminate the 5'-DMT group. Thereafter, the supports were treated with concentrated ammonia solution at room temperature for one hour to hydrolyze the succinyl linkage and the supports were filtered out. The solutions were left at room temperature and $55^{\circ} \mathrm{C}$ for one day. The study of the efficiency of the removal of protecting groups was followed by analytical HPLC. The $\mathrm{dmf}$ group was found to be the most labile protecting group, followed by the ibu group. Both groups can be removed at room temperature although the dmf group was totally removed in 2 hours, while the ibu group needed 8 hours. At the standard oligonucleotide deprotection conditions $\left(55^{\circ} \mathrm{C}\right.$, minimum 6 hours) both ibu and dmf groups are completely removed. Finally, the $\mathrm{Bz}$ group was the most stable group, although it may be removed at $55^{\circ} \mathrm{C}$ if the deprotection time is extended to 1 or 2 days. However, at room temperature the Bz group was removed very slowly (20\% in $24 \mathrm{hr}$ ).

Another important parameter in the evaluation of protected nucleosides for oligonucleotide synthesis is the stability to depurination during the removal of the dimethoxytrityl group. Previous studies have indicated that this side reaction may be important with 2-aminopurine derivatives [20]. In order to analyze the extent of the depurination reaction, the dinucleotide containing protected 2-aminopurine 5'-TP-3' was prepared using the supports carrying compounds 3 (ibu) and 5 (dmf). Dinucleotide supports were treated with a $3 \%$ TCA solution in dichloromethane during different times (up to 7 days) and then the resulting supports were treated with concentrated ammonia. Reverse-phase HPLC showed the appearance of a side product that was characterized by UV spectrometry, enzyme digestion and mass spectrometry as the depurination product. This product was quantified in relation with the dinucleotide containing 2 -aminopurine by reading the UV absorption at $260 \mathrm{~nm}$. The dinucleotide carrying dmf-protected 2-aminopurine was found to be more

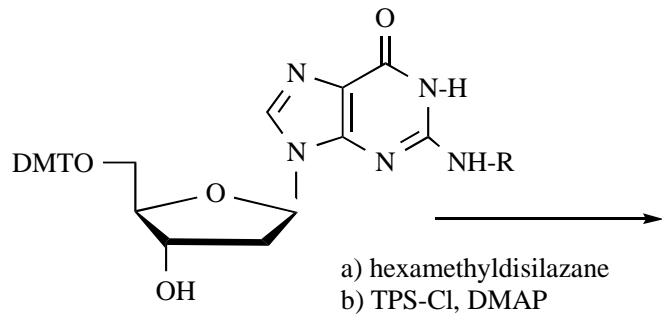

$\mathrm{R}=$ isobutyryl

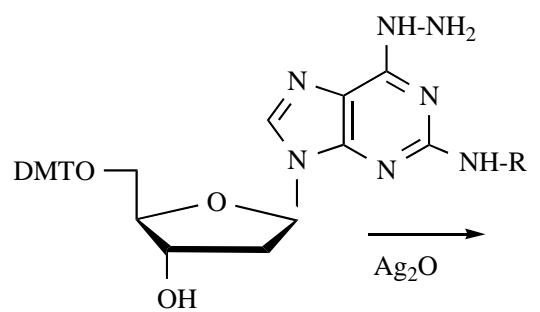

$\mathrm{R}=$ isobutyryl

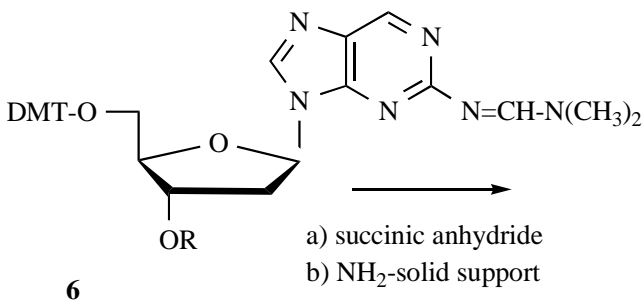

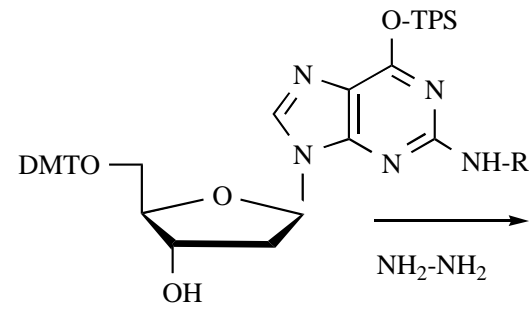

$\mathrm{R}=$ isobutyryl

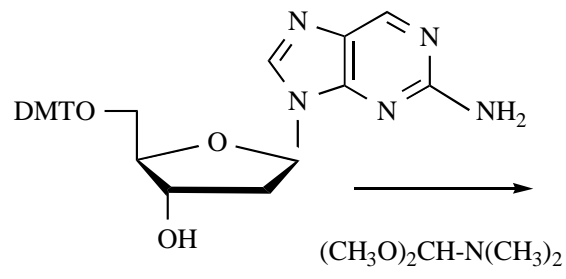

5

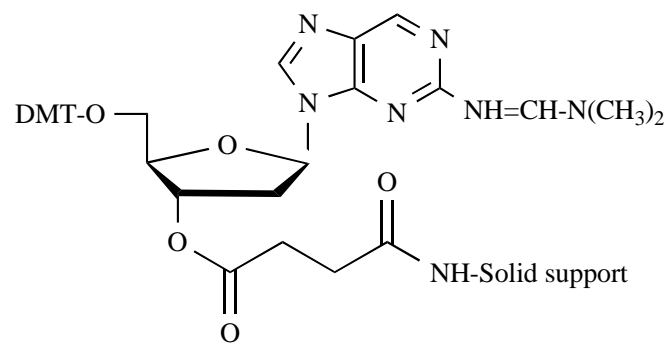

Fig. (3). Synthetic scheme used for the preparation of the solid support carrying dimethylformamidine protected 2-aminopurine. 
sensitive to depurination (half-life $\approx 2$ days) than the dinucleotide containing ibu-protected 2-aminopurine $(38 \%$ depurination after 7 days). These results allowed us to conclude that the dmf group is easier to remove, but, oligonucleotides containing 2-aminopurine with the ibu group are at least 4 times more stable to depurination than oligonucleotides carrying 2-aminopurine with the $\mathrm{dmf}$ group.

\section{Oligonucleotide Synthesis}

A series of self-complementary dodecamers carrying 2aminopurine $(\mathrm{P})$ residues P/C: (5' -CGC PAA TTC GCC-3'); P/A: (5'-CGC PAA TTA GCC-3'); P/T: (5'-CGC PAA TTT GCC-3'); and C/P: (5'-CGC CAA TTP GCC-3') were prepared using the ibu-protected 2-aminopurine phosphoramidite derivatives, and the appropriate supports. In all cases, oligonucleotides were obtained in good yields. In addition, the performance of $\mathrm{dmf}$ and ibu-protected 2-aminopurine phosphoramidites during oligonucleotide synthesis conditions was analyzed for large-scale syntheses of a short sequence containing 2-aminopurine. Sequence A (5'-CGT AGP GAT GC-3') was prepared twice on $10 \mu$ mol-scale. In the first synthesis, ibu-protected 2-aminopurine phosphoramidite (4) was used and in the second synthesis, dmfprotected 2-aminopurine phosphoramidite from commercial sources was used. Coupling efficiencies were similar for both syntheses (99\% per step). The last DMT group was left during ammonia deprotection in order to use the hydrophobicity of this group to isolate the full-length sequence from truncated sequences by reversed phase HPLC. After the first HPLC purification, a difference in the amount of full-length oligonucleotide was obtained. Using ibu-protected phosphoramidite, 363 optical density (OD) units at $260 \mathrm{~nm}$ (approx. $3.6 \mu \mathrm{mol})$ of DMT-oligonucleotide were obtained; while using dmf-protected phosphoramidite, 156 OD units at $260 \mathrm{~nm}$ (approx. $1.6 \mu \mathrm{mol}$ ) of the desired sequence were isolated. Moreover, an extra peak after the one of the desired DMT-oligonucleotide was observed only in the HPLC purification coming from the synthesis where dmf-protected 2aminopurine phosphoramidite was used. These differences could be assigned to 2-aminopurine depurination taking into account the higher sensitivity of the dmf-protected 2aminopurine derivative to acids described above. Nevertheless, some other side reactions such as premature cleavage of the dmf group or modification of protected 2-aminopurine during capping conditions or iodine oxidation may occur. Overall, the use of the ibu group for the protection of the 2aminopurine seems advantageous for large scale synthesis.

Thermal denaturation of duplexes, containing selfcomplementary sequences, were studied in $0.1 \mathrm{M}$ phosphate buffer at different $\mathrm{pH}$. In all cases a clear cooperative curve was observed. Melting temperatures are shown in Table $\mathbf{1 .}$ The most stable duplex contained 2-aminopurine: $\mathrm{T}$ base pairs. At acidic $\mathrm{pH}$, duplexes carrying 2-aminopurine: $\mathrm{C}$ base pairs are more stable than duplexes carrying 2-aminopurine: A base pairs. At neutral $\mathrm{pH}$, duplexes carrying 2aminopurine: $\mathrm{C}$ and 2-aminopurine: $\mathrm{A}$ mismatches have similar stability in agreement with published data [20,35].

\section{CONCLUSIONS}

In summary, we report the preparation of the phosphoramidite derivative of 2-aminopurine 2'-deoxyriboside protected with the ibu group, applying a route previously de- scribed for the $\mathrm{Bz}$ derivative [24]. This derivative was conveniently deprotected during standard deprotection conditions and is stable to depurination under oligonucleotide synthesis conditions. Alternatively, the dmf group was found to be more labile to ammonia but also more susceptible to depurination. Nevertheless, the extent of depurination of the dmf derivative during normal oligonucleotide synthesis conditions is small and this protecting group is a good alternative for the protection of 2-aminopurine. As described earlier $[28,30]$, the $\mathrm{Bz}$ derivative was found to be very stable to ammonia and for this reason, it is not recommended for normal use, although it could be used if the deprotection is performed during an extended period of time.

Table 1. Melting Temperatures (Tm, $\left.{ }^{\circ} \mathrm{C}\right)$ of Duplexes Containing 2-aminopurine in 0.1 M Sodium Phosphate Buffer. Self-Complemantary Sequence: 5'-CGC XAA TTY GCC-3'

\begin{tabular}{|c|c|c|c|}
\hline Sequence (X/Y) & pH 5.0 & pH 6.0 & pH 7.0 \\
\hline \hline B (P/T) & 49 & 52.7 & 53.4 \\
\hline C (P/A) & 20.5 & 22.5 & 25.5 \\
\hline D (P/C) & 24.5 & 28 & 25 \\
\hline E (C/P) & 24.5 & 28.5 & 27 \\
\hline
\end{tabular}

\section{EXPERIMENTAL SECTION}

Abbreviations used: ACN: acetonitrile, AcOEt: ethyl acetate, Ar: aromatic, CPG: controlled pore glass, DCM: dichloromethane, DMAP: $N, N$-dimethylaminopyridine, DMF: $N, N$-dimethylformamide, DMT: dimethoxytrityl, LCAA: long chain amino alkyl, $\mathrm{Me}$ : methyl, $\mathrm{MeOH}$ : methanol, P: 9-( $\beta$-D-2'-deoxyfuranosyl)-2-aminopurine, THF: tetrahydrofurane.

All ${ }^{1} \mathrm{H}-,{ }^{31} \mathrm{P}$ - and ${ }^{13} \mathrm{C}-\mathrm{NMR}$ spectra were recorded on a Brucker AM 250 spectrometer. Chemical shifts are reported in parts per million $(\delta)$ relative to the internal standard. ${ }^{13} \mathrm{C}$ NMR spectral data is reported below with broad-band proton noise decoupling; however, assignments were always made with the aid of the off-resonance data.

DMT- $N^{2}$-Bz-2-aminopurine-2'-deoxyriboside was prepared from 2'-deoxyguanosine using a multi-step synthesis scheme published previously [24-26]. 5'-O-DMT- $N^{2}$-ibu-2'deoxyguanosine was purchased from ChemGenes (USA). Chemicals for oligonucleotide synthesis were purchased from Perkin Elmer-Applied Biosystems. Anhydrous solvents were obtained from Merck (Germany) and SDS (France). The rest of the chemicals were from Aldrich (USA) and Fluka (Switzeland) and they were used directly without further purification.

\section{General Methods and Standard Work-Up}

All reactions were carried out in oven-dried glassware, under a nitrogen or argon atmosphere, unless specified otherwise. Starting materials were dried by evaporation with the dry solvent that will be used for the reaction. Once the reaction was completed, solutions were concentrated to dryness and the residues were dissolved in $\mathrm{DCM}$ or $\mathrm{CHCl}_{3}$. The re- 
sulting organic solutions were washed with $5 \%$ aqueous $\mathrm{Na}-$ $\mathrm{HCO}_{3}$ and saturated aqueous $\mathrm{NaCl}$. The organic phase was dried $\left(\mathrm{Na}_{2} \mathrm{SO}_{4}\right)$ and the solvent was removed.

\section{$3^{\prime}, 5^{\prime}-O-N^{2}$-triisobutyryl-2'-deoxyguanosine}

2'-Deoxyguanosine (4 g, $14.9 \mathrm{mmol}$ ) was dried by coevaporation with anhydrous pyridine. $50 \mathrm{~mL}$ of anhydrous pyridine and $2.35 \mathrm{~g}$ of isobutyric anhydride $(14.9 \mathrm{mmol})$ and $0.52 \mathrm{~g}$ of DMAP $(4.26 \mathrm{mmol})$ were added to the residue. The mixture was heated at $50{ }^{\circ} \mathrm{C}$ overnight. The solution was allowed to cool down at room temperature. Then, $30 \mathrm{~mL}$ of a $5 \%$ aqueous $\mathrm{NaHCO}_{3}$ solution were added and the mixture was stirred for $1 \mathrm{hr}$ at room temperature and concentrated to dryness. The residue was dissolved in $\mathrm{CHCl}_{3}$ and washed following the standard work-up described above. The product was purified by column chromatography (silica gel) eluted with a $0-4 \% \mathrm{MeOH}$ gradient in $\mathrm{CHCl}_{3}$. Yield: $6.55 \mathrm{~g}$ (13.7 mmol, 92\%). TLC (5\% MeOH in $\left.\mathrm{CHCl}_{3}\right)$ Rf 0.29. ${ }^{1} \mathrm{H}-$ $\mathrm{NMR}\left(\mathrm{CDCl}_{3}, 500 \mathrm{MHz},\right): \delta 1.14,1.15,1.23(18 \mathrm{H}, 3 \mathrm{~s}, \mathrm{ibu})$, 2.4-2.53 (6H, m, ibu), 2.77 (1H, m, H-2'), 2.99 (1H, m, H2"), 4.32 (2H, m, H-5', 5"), 4.70 (1H, m, H-4'), 5.35 (1H, m, H-3'), 6,19 (1H, t, H-1'), 7.75 (1H, s, H-8), 9.56 (1H, s, NH1), 12.20 (1H, m, NH-CO). ${ }^{13} \mathrm{C}-\mathrm{NMR}\left(\mathrm{CDCl}_{3}, 75 \mathrm{MHz}\right): \delta$ 18.7, 18.8 Me ibu), 33.7, 33.8 (CH ibu), 33.6 ( $\mathrm{CH}$ ibu), 36,6 (C-2'), 63.3 (C-5'), 74.2 (C-3'), $82.5\left(\mathrm{C}-1^{\prime}\right), 85.6$ (C-4'), 122.34 (C-5), 137.8 (C-8), 147.5 (C-4, C-2), 155.4 (C-6), 176.1 ( $\underline{\mathrm{CONH}}), 177.5,179.0\left(\underline{\mathrm{COOCH}_{2}}, \underline{\mathrm{COOCH}_{2}}\right)$.

\section{3',5'-O-N ${ }^{2}$-triisobutyryl-9-( $\beta$-D-2'-deoxyfuranosyl)-2- aminopurine (1)}

3',5'-O- $N^{2}$-Triisobutyryl-2'-deoxyguanosine was converted to 3',5'-O-N ${ }^{2}$-triisobutyryl-9-( $\beta$-D-2'-deoxyfuranosyl)-2aminopurine following a similar protocol to the one described for the benzoyl derivative [24-26]: 3',5'-O-N ${ }^{2}$ triisobutyryl-2'-deoxyguanosine $(6.5 \mathrm{~g}, 13.7 \mathrm{mmol})$ was reacted with 2,4,6-triisopropylbenzenesulfonyl (TPS) chloride (27.4 mmol), DMAP (6.85 mmol) and diisopropylethylamine $(54.2 \mathrm{mmol})$ in $85 \mathrm{~mL}$ of DCM for 2 hours at room temperature. Then, the solution was concentrated to dryness and the desired TPS derivative was isolated from the reaction mixture by silica gel chromatography eluted with a $0-5 \%$ methanol gradient in DCM.

Hydrazine hydrate $(53.6 \mathrm{mmol})$ was added to an icecooled solution of the TPS derivative in THF and the mixture was left reacting for 2 hours at room temperature. The reaction mixture was concentrated, dissolved in ethyl acetate and washed following the standard work-up protocol. The hydrazino derivative was isolated in $86 \%$ yield by silica gel chromatography eluted with a $0-2 \% \mathrm{MeOH}$ gradient in DCM. Finally, the hydrazino derivative (11.2 mmol) was dissolved in $250 \mathrm{~mL}$ of THF and heated until boiling. $\mathrm{Ag}_{2} \mathrm{O}$ (101.8 $\mathrm{mmol})$ was added to the solution in 3 portions every $30 \mathrm{~min}$. After completing the addition process, the reaction was refluxed for 2 hours. Then, the reaction mixture was concentrated to dryness before the work-up. The resulting residue was treated with ethyl acetate and $10 \% \mathrm{NaI}$ aqueous solution. The mixture was filtered through Celite and the organic phase was decanted. The organic phase was washed with $10 \% \mathrm{NaI}$ followed by $10 \%$ sodium thiosulfate and water. The product was purified by silica gel chromatography eluted with a $0-5 \% \mathrm{MeOH}$ gradient in DCM. Overall yield: $6.07 \mathrm{mmol}$ (44\% from starting $3^{\prime}, 5^{\prime}-O-N^{2}$-triisobutyryl-2'- deoxyguanosine). TLC (10\% $\mathrm{MeOH}$ in DCM) $\mathrm{Rf} 0.4 .{ }^{1} \mathrm{H}-$ NMR: $\left(\mathrm{CDCl}_{3}, 500 \mathrm{MHz}\right): \delta 1.11,1.17,1.25(18 \mathrm{H}, 3 \mathrm{~s}, \mathrm{Me}$ ibu), 2.51-2.63 (3H, m, CH ibu, H-2'), 2.99-3.01 (2H, m, CH ibu, H-2"), 4.32-4.44 (3H, m, H-5', 5", H-4'), 5.42 (1H, m, H3'), 6,42 (1H, m, H-1'), 8.14 (1H, s, H-8), 8.96 (1H, s, H-6), 8.53 (1H, s, NH-1), 12.17 (1H, m, NH-COPh). ${ }^{13} \mathrm{C}-\mathrm{NMR}$ $\left(\mathrm{CDCl}_{3}, 62 \mathrm{MHz}\right): \delta 18.7,19.1(\mathrm{Me} \mathrm{ibu}), 33.7(\mathrm{CH} \mathrm{ibu}), 35.9$ (CH ibu), 37.2 (C-2'), 63.4 (C-5'), 74.1 (C-3'), 82.8 (C-1'), 84.7 (C-4'), 131.3 (C-5), 142.8 (C-8), 149.7 (C-6), 150.9 (C4), 152.9 (C-2), 176,2, 176,5, 176,6 ( $\underline{\mathrm{CONH}}, \mathrm{COOCH}_{2}$, $\underline{\mathrm{COOCH}_{2}}$ ).

\section{$N^{2}$-isobutyryl-9-( $\beta$-D-2'-deoxyfuranosyl)-2-aminopurine} (2)

To a solution of $3{ }^{\prime}, 5 '-O-2-N$-triisobutyryl-9-( $\beta-\mathrm{D}-2$ 'deoxyfuranosyl)-2-aminopurine 1 (1.8 g, $3.9 \mathrm{mmol})$ in anhydrous pyridine $(45 \mathrm{~mL})$ and $\mathrm{MeOH}(6 \mathrm{~mL})$ cooled to $-20{ }^{\circ} \mathrm{C}$, $5.4 \mathrm{~mL}$ of a $2 \mathrm{M}$ solution of $\mathrm{NaOH}$ were added. The reaction mixture was stirred $30 \mathrm{~min}$ at $-20{ }^{\circ} \mathrm{C}$. After the solution was neutralized with Dowex 50w x 4 (pyridinium salt) until $\mathrm{pH}=$ 7. The Dowex was filtered and washed with a solution of $\mathrm{H}_{2} \mathrm{O}$ :pyridine: $\mathrm{MeOH}(3: 1: 1)$. The filtrates were evaporated to dryness and the residue was purified on a silica gel column eluted with a $0-10 \% \mathrm{MeOH}$ gradient in $\mathrm{CHCl}_{3}$. Yield $1.13 \mathrm{~g}$ (3.5 mmol, 90\%). TLC (20\% MeOH in DCM) Rf 0.15 . ${ }^{1} \mathrm{H}-\mathrm{NMR}$ as described previously [20]. ${ }^{13} \mathrm{C}-\mathrm{NMR}$ : $\left(\mathrm{CDCl}_{3}, 62 \mathrm{MHz}\right): \delta 19.6(\mathrm{Me} \mathrm{ibu}), 36.8(\mathrm{CH} \mathrm{ibu}), 41.1(\mathrm{C}-$ 2'), 63.0 (C-5'), 72.2 (C-3'), 85.7 (C-1'), 89.3 (C-4'), 132.1 (C-5), 146.0 (C-8), 149.6 (C-6), 152.9 (C-4), 154.1 (C-2), 178.4 ( $\underline{\mathrm{CONH}})$.

5'-O-DMT- $\mathrm{N}^{2}$-isobutyryl-2-aminopurine-2'-deoxyriboside3 '-O-(N,N-diisopropyl)-2-cyanoethyl phosphoramidite (4)

$N^{2}$-Isobutyryl-9-( $\beta$-D-2'-deoxyfuranosyl)-2-amino purine $2(1.2 \mathrm{~g}, 3.7 \mathrm{mmol})$ was reacted with DMT-Cl in pyridine as previously described [20].

DMT- $N^{2}$-ibu-9-( $\beta$-D-2'-deoxyfuranosyl)-2-amino purine (3, $860 \mathrm{mg}, 2.66 \mathrm{mmol})$ was reacted with $0.58 \mathrm{~mL}(2.66$ $\mathrm{mmol}$ ) of 2-cyanoethoxy- $N, N$-diisopropylamino chlorophosphine in the presence of $1.4 \mathrm{~mL}(10.64 \mathrm{mmol})$ of diisopropylethylamine as previously described [24-26]. Yield 650 $\mathrm{mg}(0.8 \mathrm{mmol}, 75 \%)$. TLC $\left(1 \% \mathrm{Et}_{3} \mathrm{~N}\right.$ in DCM) Rf 0.9. ${ }^{31} \mathrm{P}-$ NMR: $\left(\mathrm{CDCl}_{3}, 101 \mathrm{MHz}\right): \delta 149.1$ and 149.8 .

\section{5'-O-Dimethoxytrityl-9-( $\beta$-D-2'-deoxyfuranosyl)-2- aminopurine (5)}

When the procedure of McLaughlin [24] was performed with 5'-O-dimethoxytrityl- $N^{2}$-ibu-2'-deoxyguanosine the ibu group in position 2 was lost during the silver oxidation. 5'-ODMT- $N^{2}$-ibu-2'-deoxyguanosine $(2 \mathrm{~g}, 3.1 \mathrm{mmol})$ was dissolved in DMF and $0.8 \mathrm{~mL}$ of hexamethyldisilazane were added. After 3 hours of magnetic stirring the mixture was concentrated to dryness and residual DMF was eliminated by repeated evaporation with toluene. The resulting oil was dissolved in $30 \mathrm{~mL}$ of DCM and reacted with 2,4,6triisopropylbenzenesulfonyl (TPS) chloride $(6.2 \mathrm{mmol})$, DMAP (1.55 mmol) and diisopropylethylamine $(11.8 \mathrm{mmol})$ for 2 hours at room temperature. The solution was concentrated to dryness and the desired TPS derivative was isolated from the reaction mixture on a silica gel column eluted with a $0-5 \% \mathrm{MeOH}$ gradient in DCM. Yield $1.64 \mathrm{~g}(61 \%)$. To an ice-cooled solution of the TPS derivative in $20 \mathrm{~mL}$ of tetra- 
hydrofurane, $\mathrm{NH}_{2}-\mathrm{NH}_{2} \cdot \mathrm{H}_{2} \mathrm{O}(3.2 \mathrm{mmol})$ were added and the mixture was left overnight at room temperature. The reaction mixture was concentrated, dissolved in ethyl acetate and washed following the standard work-up protocol. The hydrazino derivative was isolated on a $49 \%$ yield by silica gel chromatography eluted with a $0-15 \%$ methanol gradient in DCM. Finally, the hydrazino derivative $(0.4 \mathrm{~g}, 0.67 \mathrm{mmol})$ was treated with $\mathrm{Ag}_{2} \mathrm{O}(0.81 \mathrm{mmol})$ and the mixture was refluxed overnight. The reaction mixture was concentrated to dryness before work-up. The residue was treated with ethyl acetate and a $10 \% \mathrm{NaI}$ aqueous solution. The mixture was filtered through Celite and the organic phase was decanted. The organic phase was washed with $10 \% \mathrm{NaI}$ followed by $10 \%$ sodium thiosulfate and water. The product was purified on silica gel chromatography eluted with a $0-10 \% \mathrm{MeOH}$ gradient in DCM. Yield: $120 \mathrm{mg}(32 \%)$.TLC (10\% MeOH in DCM) Rf 0.4. ${ }^{1} \mathrm{H}-\mathrm{NMR}$ : $\left(\mathrm{CDCl}_{3}, 500 \mathrm{MHz}\right): \delta 2.5(1 \mathrm{H}, \mathrm{m}$, H-2'), 2.8 (1H, m, H-2"), 3.7 (6H, s, MeO DMT), 4.2 (2H, m, H-5'), 4.7 (1H, m, H-4'), 5.2 (1H, m, H-3'), 6,3 (1H, t, H-1'), 6.7-7.4 (13H, Ar DMT), 8.1 (1H, s, H-6), 8.6 (1H, s, H-8). $\left.{ }^{13} \mathrm{C}-\mathrm{NMR}\left(\mathrm{CDCl}_{3}, 62 \mathrm{MHz}\right): \delta 39.6(\mathrm{C}-2)^{\prime}\right), 55.1(\mathrm{MeO}$, DMT), 63.7 (C-5'), 72.3 (C-3'), 83.7 (C-4'), 86.1 (C-1'), 86.4 (C $\mathrm{q}_{\mathrm{q}}$ DMT), 113.1 (DMT), 126.6 (DMT), 128.5 (C-5), 129.9 (DMT), 135.5 (DMT), 140.7 (C-8), 144.5 (DMT), 149.6 (C6), 152.7 (C-4), 158.4 (DMT), 159.6 (C-2).

\section{5'-O-Dimethoxytrityl- $N^{2}$-dimethylaminomethyliden-9- $(\beta-D$ - 2'-deoxy-furanosyl)-2-aminopurine (6)}

Compound 5 (100 mg, $0.22 \mathrm{mmol}$ ) was dissolved in 2 $\mathrm{mL}$ of $\mathrm{DMF}$ and $0.2 \mathrm{~mL}(0.24 \mathrm{mmol})$ of $N, N-$ dimethylformamide dimethyl acetal were added. After 48 hours of magnetic stirring, the solution was concentrated to dryness with a yield of $120 \mathrm{mg}(91 \%)$ of the desired product that was used in the next step without further purification. Attempts of silica gel purification did not yield the desired compound. Lost of protecting groups was observed, instead. TLC $\left(10 \% \mathrm{MeOH}\right.$ in DCM) Rf 0.4. ${ }^{1} \mathrm{H}-\mathrm{NMR}\left(\mathrm{CDCl}_{3}, 250\right.$ $\mathrm{MHz}): \delta 2.59-3.01$ (2H, m, H-2'), 3.13 (3H, d, Me dmf), 3.16 (3H, d, Me dmf), 3.74 (6H, s, MeO DMT), 3.37 (2H, m, H5'), 4.20 (1H, m, H-4'), 4.64 (1H, m, H-3'), 6.63 (1H, t, H-1'), 6.7-7.4 (13H, m, Ar DMT), 8.0 (1H, s, H-6), 8.6 (1H, s, H8), $8.8(1 \mathrm{H}, \mathrm{m}, \mathrm{CH} \mathrm{dmf}) .{ }^{13} \mathrm{C}-\mathrm{NMR}\left(\mathrm{CDCl}_{3}, 62 \mathrm{MHz}\right): \delta$ 34.8 (Me dmf), 40.8 (Me dmf), 41.1 (C2'), 54.9 (Me DMT), 63.8 (C-5'), 71.6 (C-3'), $83.0\left(\mathrm{C}^{\prime} 4^{\prime}\right), 85.9\left(\mathrm{C}-1^{\prime}\right), 86.2\left(\mathrm{C}_{\mathrm{q}}\right.$ DMT), 112.9 (DMT), 126.6 (DMT), 129.8 (DMT), 130.2 (C5), 135.4 (DMT), 141.3 (C-8), 144.4 (DMT), 148.9 (C-6), 158.1 (C-2), 158.3 (DMT), 162.6 (CH dmf).

Preparation of DMT- $N^{2}$-protected(Bz, ibu, dmf)-9-( $\beta-\mathrm{D}-$ 2'-deoxyfuranosyl)-2-aminopurine-3'-O-succinyl-LCAACPG supports.

DMT- $N^{2}-\operatorname{protected}(\mathrm{Bz} \quad[24], \quad \mathrm{ibu}, \quad \mathrm{dmf})-9-\left(\beta-\mathrm{D}-2^{\prime}-\right.$ deoxyfuranosyl)-2-aminopurine derivatives $(0.15 \mathrm{mmol})$ were dissolved in $6 \mathrm{~mL}$ of dry DCM. To these solutions 23.2 $\mathrm{mg}$ of DMAP $(0.19 \mathrm{mmol})$ and $19 \mathrm{mg}$ of succinic anhydride (0.19 mmol) were added. The mixtures were stirred at room temperature overnight. Completeness of the reactions was confirmed by careful TLC analysis. Thereafter, the mixtures were diluted with DCM and washed with $0.1 \mathrm{M}$ de $\mathrm{NaH}_{2} \mathrm{PO}_{4}$ $\mathrm{pH}=5$. The organic phases were dried and concentrated to dryness. The residues were dissolved in DCM and then precipitated on $50 \mathrm{~mL}$ of (1:1) mixture of hexane and ethyl ether. $N^{2}-\mathrm{Bz}$ derivative: Yield $70 \%$. TLC $(5 \% \mathrm{MeOH}$ in
$\left.\mathrm{CHCl}_{3}\right)$ Rf 0.35. $N^{2}$-ibu derivative: Yield 54\%. TLC (5\% $\mathrm{MeOH}$ in $\mathrm{CHCl}_{3}$ ) Rf $0.35 . \mathrm{N}^{2}$-dmf derivative: Yield $64 \%$. TLC $\left(10 \% \mathrm{MeOH}\right.$ in DCM) Rf $0.1 .{ }^{1} \mathrm{H}-$ and ${ }^{13} \mathrm{C}-\mathrm{NMR}$ confirms the addition of the succinyl group.

DMT- $N^{2}$-protected-9-( $\beta$-D-2'-deoxyfuranosyl)-2aminopurine 3'-O-succinates were reacted with aminoLCAA-CPG (500 A, loading $98 \mu \mathrm{mol} / \mathrm{g}$ ) supports following a previously described protocol [34]. Nucleoside loadings were as follows: $N^{2}$-Bz: $34 \mu \mathrm{mol} / \mathrm{g} ; N^{2}$-ibu: $52 \mu \mathrm{mol} / \mathrm{g} ; N^{2}$ dmf: $48 \mu \mathrm{mol} / \mathrm{g}$.

\section{Oligonucleotide Synthesis and Purification}

Sequence A: 5'-CGT AGP GAT GC-3' was prepared on a $10 \mu \mathrm{mol}$ scale and sequences B (P/C): 5'-CGC PAA TTC GCG-3'; C (P/A): 5'-CGC PAA TTA GCG-3'; D (P/T): 5' CGC PAA TTT GCG-3'; and E (C/P): 5'-CGC CAA TTP GCG-3' were prepared on a $1 \mu$ mol scale using the cycles implemented by the manufacturer. For the addition of the natural bases, commercially available nucleoside phosphoramidites protected with the benzoyl $(\mathrm{A}, \mathrm{C})$ and isobutyryl $(G)$ groups were used. For the preparation of sequence A two comparative $10 \mu \mathrm{mol}$-scale synthesis were performed using different 2-aminopurine phosphoramidites: the ibuprotected 2-aminopurine phosphoramidite (4) and the commercially available dmf-protected 2-aminopurine phosphoramidite. In all cases the last DMT group was left to help purification. Coupling efficiencies were 99\%. Sequence: 5'TP-3' was assembled using $35 \mathrm{mg}$ of the supports of the 2aminopurine-2'-deoxyriboside containing the ibu and the dmf groups and T 2-cyanoethyl phosphoramidite. Syntheses were performed using an automatic DNA synthesizer (Applied Biosystems Mod.392).

Sequences A-E were deprotected using standard protocols. After deprotection, sequences B-E were purified using oligonucleotide purification cartridges following the instructions of the suppliers. Further purification was achieved by reversed-phase HPLC. HPLC conditions were as follows: Column PRP-1, $10 \mu \mathrm{m},(305 \times 8 \mathrm{~mm})$, flow rate $2 \mathrm{~mL} / \mathrm{min}, 30$ min linear gradient from $5 \%$ to $40 \% \mathrm{ACN}$ over $0.1 \mathrm{M}$ aqueous triethylammonium acetate $\mathrm{pH}$ 6.5. Overall yields were: B 41\%, C 43\%, D 43\%, E 38\%. Sequence A was purified by reversed-phase HPLC using the DMT on / DMT off protocol [25]. Column PRP-1, 12-22 $\mu \mathrm{m},(250 \times 21.5 \mathrm{~mm})$, flow rate 5 $\mathrm{mL} / \mathrm{min}$, DMT on gradient: a 30 min linear gradient from $18 \%$ to $60 \% \mathrm{ACN}$ over $0.1 \mathrm{M}$ aqueous triethylammonium acetate $\mathrm{pH}$ 6.5; DMT off gradient: a 30 min linear gradient from $5 \%$ to $50 \% \mathrm{ACN}$ over $0.1 \mathrm{M}$ aqueous triethylammonium acetate $\mathrm{pH}$ 6.5. After the first HPLC purification (DMT-on) the amounts of DMT-oligonucleotide obtained were 363 OD (using the ibu group for 2-aminopurine) and $156 \mathrm{OD}$ (using the dmf group for the 2-aminopurine). After the second HPLC (DMT off) 276 OD (ibu) and 111 OD (dmf) were obtained.

The nucleoside composition of the oligonucleotides carrying 2-aminopurine was confirmed by hydrolysis with snake venom phosphodiesterase and alkaline phosphatase followed by HPLC analysis [20]. The oligonucleotide 5'CGC PAA TTC GCG-3' was further analyzed by mass spectrometry (electrospray): found 3629.6 expected for $\mathrm{C}_{116} \mathrm{H}_{147} \mathrm{~N}_{46} \mathrm{O}_{69} \mathrm{P}_{11} 3629.9$. 
Deprotection Studies for Bz-, ibu- and dmf-protected 2aminopurine-2'-deoxyriboside

Supports containing 5'-O-DMT- $N^{2}-(\mathrm{Bz}-$, ibu- or dmf)protected 2-aminopurine 2'-deoxyriboside were detritylated with 3\% TCA in DCM. Aliquots of the different supports (5 $\mathrm{mg}$ each) were treated with concentrated ammonia $(1 \mathrm{~mL})$ and were left at room temperature and $55^{\circ} \mathrm{C}$ for different periods of time. Then, the solutions were concentrated to dryness and analyzed by reverse-phase HPLC.

\section{Depurination Studies}

Aliquots of the 5'-TP-3'-succinyl-CPG were treated with 3\% TCA solution in DCM at room temperature for different times up to 7 days. The supports were filtered, washed with $\mathrm{ACN}$ and dried. The resulting supports were treated with concentrated ammonia at $55^{\circ} \mathrm{C}$ for 2 hours and the solutions were concentrated to dryness. The resulting products were analyzed by reverse-phase HPLC (see conditions in oligonucleotide synthesis and purification). The depurination product eluted $0.5 \mathrm{~min}$ after the peak corresponding to the dimer containing 2-aminopurine. 5'-TP-3' dinucleotide: UV (water pH 6.5) max $252(\mathrm{P}), 268(\mathrm{~T})$ and $307(\mathrm{P}) \mathrm{nm}$; enzyme digestion showed the presence of 2-aminopurine 2'-deoxyriboside and thymidine; mass spectra $\mathrm{M}=555.3$ (expected for $\mathrm{C}_{20} \mathrm{H}_{26} \mathrm{~N}_{7} \mathrm{O}_{10} \mathrm{P}$ 555.4). Depurination product. UV (water $\mathrm{pH}$ 6.5) $\max 270(\mathrm{~T}) \mathrm{nm}$, enzyme digestion showed only the presence of thymidine, mass spectra $\mathrm{M}=438$ (expected for $\mathrm{C}_{15} \mathrm{H}_{23} \mathrm{~N}_{2} \mathrm{O}_{11} \mathrm{P} 438.3$ ).

\section{Melting Studies}

Oligonucleotides $\mathrm{P} / \mathrm{C}, \mathrm{P} / \mathrm{A}, \mathrm{P} / \mathrm{T}$ and $\mathrm{C} / \mathrm{P}$ were dissolved in a solution of $0.1 \mathrm{M}$ sodium phosphate buffer at different pHs. The solutions were heated at $80^{\circ} \mathrm{C}$ and allowed to cool slowly to $4^{\circ} \mathrm{C}$. UV absorption spectra and melting experiments (absorbance $v s$ temperature) were recorded in $1 \mathrm{~cm}$ path-length cells with a spectrophotometer, which has a temperature controller with a programmed temperature increase of $0.5 \mathrm{deg} \mathrm{min}^{-1}$. Thermal denaturation curves were run on duplex concentration of $4 \mu \mathrm{M}$ at $260 \mathrm{~nm}$.

\section{ACKNOWLEDGEMENTS}

This work was supported by the Spanish Ministry of Education (grant CTQ2010-20541) and the Generalitat de Catalunya (2009/SGR/208).

\section{REFERENCES}

[1] Beaucage, S.L.; Iyer, R.P. Synthetic oligodeoxynucleotides containing modified bases. Tetrahedron, 1993, 49(28), 6123-6194.

[2] Sowers, L.C.; Fazakerley, G.V.; Eritja, R.; Kaplan, B.E. Base pairing and mutagenesis: observation of a protonated base pair between 2-aminopurine and cytosine in an oligonucleotide by proton NMR. Proc. Natl. Acad. Sci. USA, 1986, 83(15), 5434-5438.

[3] Lycksell, P.O.; Gräslund, A.; Claesens, F.; McLaughlin, L.W.; Larsson, U.; Rigler, R. Base pair opening dynamics of a 2aminopurine substituted Eco RI restriction sequence and its unsubstituted counterpart in oligonucleotides. Nucleic Acids Res., 1987, 15(21), 9011-9026.

[4] Aiken, C.R C.R.; Gumport, R.I. Base analogs in study of restriction enzyme-DNA interactions. Methods Enzymol., 1991, 208, 433-449.

[5] Petrauskene, O.V.; Schmidt, S.; Karyagina, A.S.; Nikolskaya, I.I.; Gromova, E.S.; Cech, D. The interaction of DNA duplexes containing 2-aminopurine with restriction endonucleases EcoRII and SsoII. Nucleic Acids Res., 1995, 23(12), 2192-2197.
[25] Connolly, B.A. Synthetic oligodeoxynucleotides containing modified bases. Methods Enzymol., 1992, 211, 36-53.

[26] Connolly, B.A. in Oligonucleotides and Analogs. A practical approach., Eckstein, F. Ed., IRL Press, New York 1991, pp. 155-183.

[27] Doudna, J.A.; Szostak, J.W.; Rich, A.; Usman, N. Chemical synthesis of oligoribonucleotides containing 2-aminopurine: substrates

Diekmann, S.; von Kitzing, E.; McLaughlin, L.; Ott, J.; Eckstein, F.
The influence of exocyclic substituents of purine bases on DNA curvature. Proc. Natl. Acad. Sci. USA, 1987, 84(23), 8257-8261.

Diekmann, S.; McLaughlin, L. DNA curvature in native and modified EcoRI recognition sites and possible influence upon the endonuclease cleavage reaction. J. Mol. Biol., 1988, 202(4), 823-834.

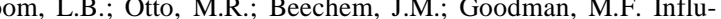
cent of 5 -nearest neighbors on the insertion kinetics of the fluoreschemistry, 1993, 32(41), 11247-11258.

Bloom, L.B.; Otto, M.R.; Eritja, R.; Reha-Krantz, dependent nucleotide excision by the 3'-exonuclease activity of bacteriophage T4 DNA polymerase. Biochemistry, 1994, 33(24), 7576-7586. in analog 2-aminopurine as a spectroscopic probe of nucleotide erase I and bacteriophage T4 DNA polymerase. Biochemistry, 1995, 34(28), 9185-9192.

Hochstrasser, R.A.; Carver, T.E., Sowers, L.C.; Millar, D.P. Melting of a DNA helix terminus within the active site of a DNA polymerase. Biochemistry, 1994, 33(39), 11971-11979.

cence-based assay for monitoring helicase activity. Proc. Natl. Acad. Sci. USA, 1994, 91(14), 6644-6648.

Allan, B.W.; Reich, N.O. Targeted base stacking disruption by the 14762 .

Holz, B.; Klimasaukas, S.; Serva, S.; Weinhold, E. 2-Aminopurine ferases. Nucleic Acids Res., 1998, 26(4), 1076-1083.

Guest, C.R.; Hochstrasser, R.A.; Sowers, L.C.; Millar, D.P. Dynamics of mismatched base pairs in DNA. Biochemistry, 1991, 30(13), 3271-3279. taining 2-aminopurine. Biochemistry, 1996, 35(38), 12329-12337. Fazakerley, G.V.; Sowers, L.C.; Eritja, R.; Kaplan, B.E.; Goodman, M.F. NMR studies on an oligodeoxynucleotide containing 2aminopurine opposite adenine. Biochemistry, 1987, 26(18), 56415646. Goodman, M.F.; Fazakerley, G.V. Characterization of the high pH wobble structure of the 2-aminopurine.cytosine mismatch by N-15 NMR spectroscopy. Biochem. Biophys. Res. Comm., 1989, 165(1), 89-92.

Fagan, P.A.; Fàbrega, C.; Eritja, R.; Goodman, M.F.; Wemmer, D.E. NMR study of the conformation of the 235(13), 4026-4033. gomers containing base mispairs involving 2-aminopurine. Nucleic Acids Res., 1986, 14(14), 5869-5884. Phage T4. J. Mol. Biol., 1959, 1(2), 87-105.

tion mutations: frequencies of forming 2 -aminopurine cytosine and adenine.cytosine base mispairs in vitro. Proc. Natl. Acad. Sci. USA, 1981, 78(5), 2864-2868.

Sowers, L.C.; Mhaskar, D.N.; Khwaja, T.A.; Goodman, M.F. Preparation of imino and amino N-15 enriched 2-aminopurine deoxynucleoside. Nucleosides Nucleotides 1989, 8(1), 23-34.

Laughlin, L.W.; Leong, T.; Benseler, F.; Piel, N. A new apthe synthesis of a protected 2-aminopurine derivative and its incorporation into oligodeoxynucleotides containing the Eco RI and Bam HI recognition sites. Nucleic Acids Res., 1988, 16(12), 5631-5644.

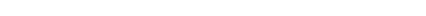


for the investigation of ribozyme function. J. Org. Chem., 1990, 55(21), 5547-5549.

[28] Schmidt, S.; Cech, D. A new approach to the synthesis of 2aminopurine-2'-deoxyriboside via tri-n-butyltin hydride reduction. Nucleosides Nucleotides, 1995, 14(6), 1445-1452.

[29] Fujimoto, J.; Nuesca, Z.; Mazurek, M.; Sowers, L.C. Synthesis and hydrolysis of oligodeoxyribonucleotides containing 2-aminopurine. Nucleic Acids Res., 1996, 24(4), 754-759.

[30] Zhou, Y.; Ts'o, P.O.P. Synthesis of oligodeoxyribonucleotide methylphosphonate containing 2-aminopurine. Nucleosides $\mathrm{Nu}$ cleotides, 1996, 15(10), 1635-1648.

[31] Acedo, M.; Fàbrega, C.; Aviñó, A.; Goodman, M.F.; Fagan, P.; Wemmer, D.; Eritja, R. A simple method for N-15 labelling of exocyclic amino groups in synthetic oligodeoxynucleotides. $\mathrm{Nu}$ cleic Acids Res., 1994, 22(15), 2982-2989.
[32] McBride, L.J.; Kierzek, R.; Beaucage, S.L.; Caruthers, M.H. Amidine protecting groups for oligonucleotide synthesis. 16. J. Am. Chem. Soc., 1986, 108(8), 2040-2048.

[33] Vu, H.; McCollum, C.; Jacobson, K.; Thiesen, P. Fast oligonucleotide deprotection phosphoramidite chemistry for DNA-synthesis. Tetrahedron Lett., 1990, 31(50), 7269-7272.

[34] Gupta, K.C.; Kumar, P.; Bhatia, D.; Sharma, A.K. A rapid method for the functionalization of polymer supports for solid phase oligonucleotide synthesis. Nucleosides Nucleotides 1995, 14(3-5), 829-832.

[35] Gargallo, R.; Vives, M.; Tauler, R.; Eritja R. Protonation studies and multivariate curve resolution on oligodeoxynucleotides carrying the mutagenic base 2-aminopurine. Biophys. J., 2001, 81(5), 2886-2896.

(C) Fàbrega et al.; Licensee Bentham Open.

This is an open access article licensed under the terms of the Creative Commons Attribution Non-Commercial License (http://creativecommons.org/licenses/by-nc/3.0/) which permits unrestricted, non-commercial use, distribution and reproduction in any medium, provided the work is properly cited. 